\title{
5 years Experience in the Treatment of GIST Tumors in the Virgen Macarena University Hospital
}

Research Article

Capitán Morales Luis $\mathrm{C}^{1}$, Perales I ${ }^{1,2}$, Gómez-Rosado J.C ${ }^{2}$, Valdés J ${ }^{2}$, Del Río F ${ }^{1,2}$, Cintas J ${ }^{1}$, Torres - $C^{2}$, Pérez A ${ }^{1}$, Oliva F $\mathrm{F}^{1,2}$

${ }^{1}$ Unit of Colorectal Surgery, Clinical Management, Virgen Macarena University Hospital of Seville, Spain.

${ }^{2}$ Unit of General and Digestive Surgery, Faculty of Medicine - University of Seville, Spain.

\section{Abstract}

Introduction: Gastrointestinal stromal tumors (GIST) are the most common and diagnosed mesenchymal tumors. Its most frequent location is the stomach, and although they are very heterogeneous, most of them present mutations for the KIT receptor or for the platelet-derived growth factor receptor PDGRA. Even so, the clinical manifestations will depend mostly on their location and size, without being GIST identifying characteristics. This great variability makes it difficult to elaborate diagnostic protocols, as well as guidelines and universal treatment algorithms. Thus, they are usually diagnosed accidentally during the study of other pathologies. The main difference with other gastrointestinal neoplasms is the impossibility of predicting GIST malignancy based on the histopathological study, which is also limited to a submucosal location of the lesion. In addition, we also find great variability at the macroscopic level, which complicates the preoperative assessment by imaging. It seems that the malignant potential resides in the inherent characteristics of the tumor and not so much in its progression, which explains the need in some patients for prolonged treatment even after the tumor has been removed. Even so, the gold standard treatment in GIST is surgical resection, although, thanks to the mutations that they present, target therapies with inhibitors of the tyrosine kinase receptors in advanced and metastatic GISTs can be used.

Objective of the study: To know the results in safety and efficacy of the surgical treatment of GIST, as well as to establish the comparative between open and laparoscopic approach, and to analyze the coincidences with the literature.

Materials and methods: We collected 40 cases of GIST diagnosed and operated by the General Surgery Service at the Virgen Macarena University Hospital (Seville) in the last four years (2012-2016), where age, sex, tumor location and surgical factors are analyzed.

Results: The mean age of the patients was 58.76 years, with the median being 60 years, with $51.43 \%$ women (18) of 57.56 years on average, and $48.57 \%$ men (17). ), of 60.2 years on average. There are the same number of cases located in the stomach as in the small intestine (15 patients, $42.86 \%)$, followed by colon, $(5.71 \%)$, pancreas $(5.71 \%)$ and greater omentum $(2.86 \%)$., among which there are 5 cases of recurrence. $80 \%$ of the cases $(28)$ were operated on by open surgery, and of all the interventions, $91.43 \%$ were performed by specialist physicians and $8.57 \%$ by medical residents. A $8.57 \%$ of the cases had to be reoperated urgently by open approach, with postoperative complications appearing in $5.71 \%$.

Discussion: Comparing our results with the literature regarding the diagnosis and therapeutic management of GIST tumors collected in our series.

Conclusion: The results collected in this study conform to the most significant publications, despite the small sample size. The morbidity of surgical treatment can be considered minimal, and the protocol, safe. The comparison between laparoscopy and open surgery does not influence the stay of patients but is more beneficial in terms of the appearance of complications. However, our study is limited by the absence of prognostic data.

Abbreviations: GIST: Gastrointestinal Stromal Tumors.

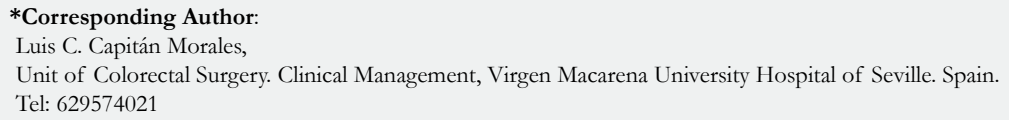

Citation: Capitán Morales Luis C, Perales I, Gómez-Rosado J.C, Valdés J, Del Río F, Cintas J, et al.,. 5 years Experience in the Treatment of GIST Tumors in the Virgen Macarena University Hospital. Int J Surg Res. 2019;6(1):123-131. doi: http://dx.doi.org/10.19070/2379-156X-1900027

Copyright: Capitan-Morales LC $^{\circ}$ 2019. This is an open-access article distributed under the terms of the Creative Commons Attribution License, which permits unrestricted use, distribution and reproduction in any medium, provided the original author and source are credited. 


\section{Introduction}

The GIST (gastrointestinal stromal tumor) constitutes the majority of gastrointestinal sarcomas and have differentiating characteristics that identify them. Initially, the GIST were classified as leiomyomas, leiomyosarcomas and leiomyoblastomas, according to their structure under optical microscope. It was the description of its ultrastructure and its immunohistochemical markers that allowed to determine the correct non-muscular origin of them [1]. Their cells have genotypic similarities with Cajal intestinal pacemaker cells: both express a marker of hematopoietic progenitor cells, CD34+ and growth factor receptor c-KIT, the expression of the latter's protein product, CD117, being a defining characteristic important of the GIST.

From a clinical point of view, GISTs are extremely heterogeneous, being impossible to predict a benign or malignant character from their histopathology. The spectrum of behavior ranges from GIST that remain dormant throughout life without requiring any treatment, to GIST multifocal of rapid dissemination that require intense multidisciplinary treatment, being in many cases resistant to it [2].

There is a sporadic function gain of the transmembrane receptor tyrosine kinase (c-KIT) when mutating its genetic sequence, altering the cell cycle when cell hyperproliferation is induced [1]. Mutation of the KIT receptor gene is present in almost $80 \%$ of the GISTs, while between $5 \%$ and $10 \%$, the gene for the plateletderived growth factor receptor PDGFRa (polypeptide gene that codes for receptor) will be mutated type III tyrosine kinase, homolog of c-KIT).

GISTs have been considered as rare tumors, mainly due to their incorrect classification. Nowadays, they are the most frequent gastrointestinal tumors, once it was known that many of the neoplasms that under the optical microscope corresponded to muscle or nervous tumors, were actually GISTs [2].

The majority of GIST tumors are small, between 1 and $20 \mathrm{~cm}$. The most common locations are stomach $(50 \%-70 \%$, associated with better prognosis) and small intestine (20\% - 30\%), but can appear at any level of the digestive tract. Esophagus, colon and rectum constitute less than $10 \%$, being very infrequent, although possible, its appearance in greater omentum, appendix and gallbladder [3].

The average age of appearance is between 55 and 60 years of age, equally in men and women, although they can appear at any age. GIST in patients under 40 years of age do not usually express a KIT or PDGFRA mutation, but they do find mutations of loss of function in the SDH complex (succinate dehydrogenase) with increasing frequency [4]. These tumors are clinically and morphologically distinct from the rest of GIST: they are generally located in the stomach, their response to treatment is poorer and they tend to invade lymph nodes and vessels [5].

GIST tumors, in addition to constituting themselves as an entity and localized throughout the gastrointestinal tract, may be outside the limits of the same, or simultaneously at several levels, even outside the digestive system, or associated with familial syn- dromes.

There have been cases of primary extragastrointestinal GISTs (EGISTs), although the majority corresponded in fact to metastasis of primary GISTs located within the digestive tract, which is why immunohistochemical identification is essential.

The appearance of multiple lesions, in the same or different locations, constitutes an exceptional event, and is not related to an increase in aggressiveness, although it is related to prognosis and treatment. We can find sporadic tumors, such as the family syndrome (autosomal dominant) or as a complementary manifestation of other syndromes. In these cases, the diagnosis will not be so much immunohistochemical but clinical, based on the complete syndromic picture [6].

On the other hand, cases of familial GIST syndrome have been reported, a very rare disorder of autosomal dominant inheritance, which causes the appearance of one or more GIST in two or more members of the family.

Gastric GIST [7] is the most frequent location, diagnosed between 63 and 70 years and less than 10\% below 40 years, being slightly more frequent in men (55\%). Its frequency of malignancy is estimated between 20 and $25 \%$ of all cases, and can invade locally spleen, pancreas and transverse colon, making necessary the en bloc resection of these organs together with the stomach, so that the surgery can be curative.

GISTs located in the duodenum [8] constitute $4-5 \%$ of all cases, being able to appear anywhere but being more common in the second portion. Due to its location, in those cases in which the tumor is located in the second portion, it can invade the pancreas and simulate a pancreatic tumor.

In the jejunum and ileum, $30 \%$ of the cases of GIST are located, more common in the jejunum. In general, they tend to be more malignant, presenting a mortality of $40-50 \%$, even higher if the tumor exceeds $5 \mathrm{~cm}$ or its mitotic index is higher than 5 mitosis $/ 50$ fields.

GISTs located in the colon are very rare (1-2\% of the total), their appearance being more common in the left colon, around 60 years of age. Several studies show that the main prognostic factor corresponds to the high mitotic index.

The appearance in the rectum is approximately $4 \%$, from small tumors found coincidentally during a prostate or pelvic examination, to sarcomas [9] of large size, which are usually symptomatic causing obstruction and bleeding.

In general, it is more frequent to diagnose them by upper gastrointestinal endoscopy, abdominal CT or both as a casual result in asymptomatic patients (30\% of GIST are) or in the study for symptoms such as early satiety, abdominal pain or gastrointestinal bleeding, constituting the first diagnostic steps of GIST. For GIST in the small intestine, a standard endoscopic examination may not be sufficient, requiring advanced techniques such as double-balloon endoscopy or capsule [10].

Tumor size is an important prognostic factor, as well as mitotic 
activity, which classifies them as $<5$, between 5 and 10 , and $>10$ mitosis per field. Within the anatomopathological risk criteria, in addition to these, the tumor site is included. The staging of the tumor is essential for the selection of patients in whom adjuvant treatment will be beneficial.

For therapeutic planning, endoscopic study is complemented with imaging studies in all patients. This will include CT with contrast and MRI, both used to evaluate the extent of the primary tumor in relation to adjacent organs, as well as the detection of possible metastases [2]. When it comes to staging GIST in a preoperative study, PET offers many advantages, being able to show early metastases and demonstrating tumor metabolic activity. It is very sensitive, also, to control the early response to treatment with imatinib and predict the long-term response in the presence of metastasis. A pre-treatment study should be performed to establish comparisons during this surveillance using PET.

Unguided biopsy establishes a definitive diagnosis for subepithelial masses in only $20-30 \%$ of cases, so that to improve performance, ultrasound-guided FNA is used [11].

The main difficulty lies in obtaining a tissue sample suitable for the histological study. In sub-epithelial lesions of less than $2 \mathrm{~cm}$, surveillance is accepted without histological diagnosis or treatment until progression is observed. It is common to find subclinical GIST without relevance in series of autopsies.

If the location of the lesion is accessible and surgical removal with low morbidity is possible, this can be done without having obtained a previous sample for its study. Neither is histological diagnosis necessary in extensive lesions where surgery is clearly indicated only with radiological study.

For the preoperative study, obtaining sample tissue should preferably be done endoscopically, but if it is possible, it could be done percutaneously guided by ultrasound, CT or MRI, taking extreme precautions so as not to cause a tumor effusion [12].

In the presence of a localized gastric GIST smaller than $2 \mathrm{~cm}$, as well as for non-gastric GISTs of any size, the treatment of choice is complete surgical resection, achieving healing in approximately $60 \%$ of patients [13]. Even in locally advanced tumors, resection is indicated, as it is associated with increased survival. The fiveyear survival rate (without surgery) varies between $20 \%$ and $44 \%$, while in patients treated by complete resection, it rises to almost $75 \%$. Lymphatic dissection is not usually necessary, as lymphatic metastases rarely occur.

\section{Objectives of the Study}

To know the results of the surgical treatment of the General Surgery Service of the University Hospital Virgen Macarena of GIST tumors in terms of safety and efficacy.

\section{Secondary objectives}

To know the results of conventional versus laparoscopic surgery in the treatment of these tumors. Analysis of coincidences between our results and the most recent international publications regarding the surgical treatment of GIST.

\section{Material and Methods}

Between July 2012 and November 2016, 40 patients diagnosed with GIST were received at the General Surgery Department of the University Hospital Virgen Macarena, for surgical treatment.

This list of cases is received correctly anonymized according to the Organic Law of Protection of Personal Data, Law 15/99 of December 13, keeping its strict confidentiality and not accessing unauthorized third parties. In the same way, the actions carried out will not imply any repercussion on the subjects of the study or the persons related to it, respecting the right to privacy, in accordance with the provisions of Law 41/2002, of November 14, basic regulating patient autonomy and rights and obligations in terms of information and clinical documentation.

Thus, the 40 cases were reviewed, of which finally five are excluded, as they are not susceptible to surgical treatment and, therefore, they are not the reason for the present study. Of the 35 cases included, the following factors are analyzed:

\section{- Age \\ - Sex \\ - Location. \\ - Recurrences \\ - Comorbidities \\ - Surgical approach \\ - Laparoscopic conversion \\ - Surgical technique \\ - Surgeon's experience \\ - Stay \\ - Reinterventions \\ - Complications}

\section{Results}

All the patients selected for study were diagnosed with GIST and followed by the Oncology service, as well as treated by surgery. The five patients who, even initially considered for surgery, were finally susceptible to medical treatment, have been eliminated ( $\mathrm{Ta}-$ ble 2), leaving a total of 35 patients. The clinical and surgical characteristics analyzed are shown in Table 3 Age and sex.

The average age of the patients was of 58.76 years, being $51.43 \%$ women (18) with an average age of 57.56 years, and $48.57 \%$ men (17), with average age 60.2 years old. The median age is 60 years. In both sexes, we found a greater number of cases between 60 and 69 years (10 patients, $28.58 \%$ ); however, in the group of women there are more cases between 50 and 59 years ( 6 women, $15.24 \%$ of the total of patients). Likewise, they are diagnosed within a wide age range ( 35 years -84 years).

\section{Location}

We found the same number of cases of gastric GIST as of GIST located in the small intestine (15 patients, $42.86 \%)$. The distribution by sex is detailed in Table 2, but we can emphasize that in case of gastric GIST, the cases are women were more numerous (6) than in men (4), unlike in the small intestine. Of the 5 cases remaining, we located 2 in the pancreas $(5.71 \%), 2$ in the colon 
Table 1. Patients excluded from the study.

Patients excluded from the study : total: 5

\begin{tabular}{|c|c|c|}
\hline \multirow{3}{*}{ Age } & $50-59$ & $2(40 \%)$ \\
\cline { 2 - 3 } & $70-79$ & $2(40 \%)$ \\
\cline { 2 - 3 } & $80-89$ & $1(20 \%)$ \\
\hline \multirow{2}{*}{ Sex } & Women & $2(40 \%)$ \\
\cline { 2 - 3 } & Men & $3(60 \%)$ \\
\hline \multirow{2}{*}{ Location } & Stomach & $2(40 \%)$ \\
\cline { 2 - 3 } & Small bowel & $3(60 \%)$ \\
\hline
\end{tabular}

Table 2. Cases per year.

\begin{tabular}{|c|c|c|c|c|}
\hline Total cases: $\mathbf{3 5}$ & \multicolumn{4}{|l|}{} \\
\hline 2012 & 2013 & 2014 & 2015 & 2016 \\
\hline 6 & 7 & 7 & 8 & 7 \\
\hline
\end{tabular}

Table 3. Clinical and surgical characteristics.

Selected patients: total: 35

\begin{tabular}{|c|c|c|}
\hline \multicolumn{3}{|l|}{ Patients N (\%) } \\
\hline \multicolumn{2}{|l|}{ Age (average) } & 58 years \\
\hline \multicolumn{2}{|l|}{ Age (median) } & 60 years \\
\hline \multirow{19}{*}{ Age (by range) } & \multirow{3}{*}{$30-39 y$} & $2(5.71 \%)$ \\
\hline & & Men: $1(2.855 \%)$ \\
\hline & & Women: $1(2.855 \%)$ \\
\hline & \multirow{3}{*}{$40-49 y$} & $6(17.14 \%)$ \\
\hline & & Men: $3(8.57 \%)$ \\
\hline & & Women: $3(8.57 \%)$ \\
\hline & \multirow{3}{*}{$50-59 y$} & $8(22.86 \%)$ \\
\hline & & Men: $2(7.62 \%)$ \\
\hline & & Women: $6(15.24 \%)$ \\
\hline & \multirow{3}{*}{$60-69 y$} & $10(28.57 \%)$ \\
\hline & & Men: $5(14.285 \%)$ \\
\hline & & Women : $5(14.285 \%)$ \\
\hline & \multirow{3}{*}{$70-79 y$} & $6(17.14 \%)$ \\
\hline & & Men: $3(8.57 \%)$ \\
\hline & & Women: $3(8.57 \%)$ \\
\hline & \multirow{3}{*}{$80-89 y$} & $1(2.86 \%)$ \\
\hline & & Men: $1(2.86 \%)$ \\
\hline & & Women: $0(0 \%)$ \\
\hline & undetermined & $2(5.71 \%)$ \\
\hline \multirow{4}{*}{ Sex } & \multirow{2}{*}{ Women } & $18(51.43 \%)$ \\
\hline & & Middle ages: 57.56 \\
\hline & \multirow{2}{*}{ Men } & $17(48.57 \%)$ \\
\hline & & Middle ages: 60.2 \\
\hline
\end{tabular}




\begin{tabular}{|c|c|c|c|}
\hline \multirow{13}{*}{ Location } & \multirow{3}{*}{ Stomach } & \multicolumn{2}{|l|}{$15(42.86 \%)$} \\
\hline & & \multicolumn{2}{|l|}{ Men: $6(17.14 \%)$} \\
\hline & & \multicolumn{2}{|c|}{ Women : $9(25.71 \%)$} \\
\hline & \multirow{3}{*}{ Small bowel } & \multicolumn{2}{|c|}{$15(42.86 \%)$} \\
\hline & & \multicolumn{2}{|l|}{ Men: $9(25.71 \%)$} \\
\hline & & \multicolumn{2}{|c|}{ Women: $6(17.14 \%)$} \\
\hline & \multirow{3}{*}{ Pancreas } & \multicolumn{2}{|c|}{$2(5.71 \%)$} \\
\hline & & \multicolumn{2}{|l|}{ Men :1 (2.86\%) } \\
\hline & & \multicolumn{2}{|c|}{ Women: $1(2.86 \%)$} \\
\hline & \multirow{3}{*}{ Colon } & \multicolumn{2}{|l|}{$2(5.71 \%)$} \\
\hline & & \multicolumn{2}{|l|}{ Men :1 $(2.86 \%)$} \\
\hline & & \multicolumn{2}{|c|}{ Women: $1(2.86 \%)$} \\
\hline & Greater momentum & \multicolumn{2}{|l|}{$1(2.86 \%)$, woman } \\
\hline \multirow{3}{*}{\multicolumn{2}{|c|}{ Recurrences }} & \multicolumn{2}{|c|}{$5(14.29 \%$ of the total cases $)$} \\
\hline & & Men: $2(5.71 \%)$ & \\
\hline & & Women: $3(8.57 \%$ & \\
\hline Comorbidities & & 6 cases $(17.14 \%)$ & \\
\hline Surgical aspects & & & \\
\hline & & $28(80 \%)$ & \\
\hline & & Stomach: & $9(25.71 \%)$ \\
\hline & & Of the 15 cases & $60 \%$ \\
\hline & & Small bowel & $14(40 \%)$ \\
\hline & & Of the 15 cases & $93.33 \%$ \\
\hline & Open & Colon: & $2(5.71 \%)$ \\
\hline & & Of the 15 cases & $100 \%$ \\
\hline Annroach & & Pancreas & $2(5.71 \%)$ \\
\hline Approacn & & Of the 2 cases & $100 \%$ \\
\hline & & Soft parts & $1(2.86 \%)$ \\
\hline & & From 1 case & $100 \%$ \\
\hline & & $7(20 \%)$ & \\
\hline & & Stomach & $6(17.14 \%)$ \\
\hline & Laparoscopy & Of the total & $46 \%$ \\
\hline & & Small bowel & $1(2.86 \%)$ \\
\hline & & Of the total & $8 \%$ \\
\hline Laparoscopic conversión & & $\begin{array}{l}2 \text { cases }(5.71 \%) \\
\text { total laparoscopic }\end{array}$ & $77 \%$ Of the \\
\hline & Partial gastrectomy & 14 cases $(40 \%)$ & \\
\hline & Intestinal resection & 12 cases $(34.26 \%$ & \\
\hline & Exploratory laparotomy & 4 cases $(11.43 \%)$ & \\
\hline Surgical technique & Partial Colectomy & 2 cases $(5.71 \%)$ & \\
\hline & Total gastrectomy & 1 case $(2.86 \%)$ & \\
\hline & Pancreatectomy & 1 case $(2.86 \%)$ & \\
\hline & Removal of greater momentum & 1 case $(2.86 \%)$ & \\
\hline Suroeon's exnerience & Staff & 32 interventions & $3 \%)$ \\
\hline 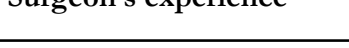 & Resident & 3 interventions $(\varepsilon$ & \\
\hline Tyne of income & Urgent & $5(14.29 \%)$ & \\
\hline 1Уре 0i interinte & Programmed & $30(85.71 \%)$ & \\
\hline & TOTAL & 10,91 days & \\
\hline Stay (average) & Laparoscopy & 9,14 days & \\
\hline & Open & 11,36 days & \\
\hline & TOTAL & 8,23 & \\
\hline Stay (SD) & Laparoscopy & 9,28 & \\
\hline & Open & 8,07 & \\
\hline Reinterventions & 1 & 3 cases $(8.57 \%)$ & \\
\hline Keinterventions & 2 & 1 case $(33.33 \%)$ & \\
\hline Complications & & 2 cases $(5.71 \%)$ & \\
\hline
\end{tabular}




\section{Graph 1. Dispersion of the age of appearance of GIST of the sample.}

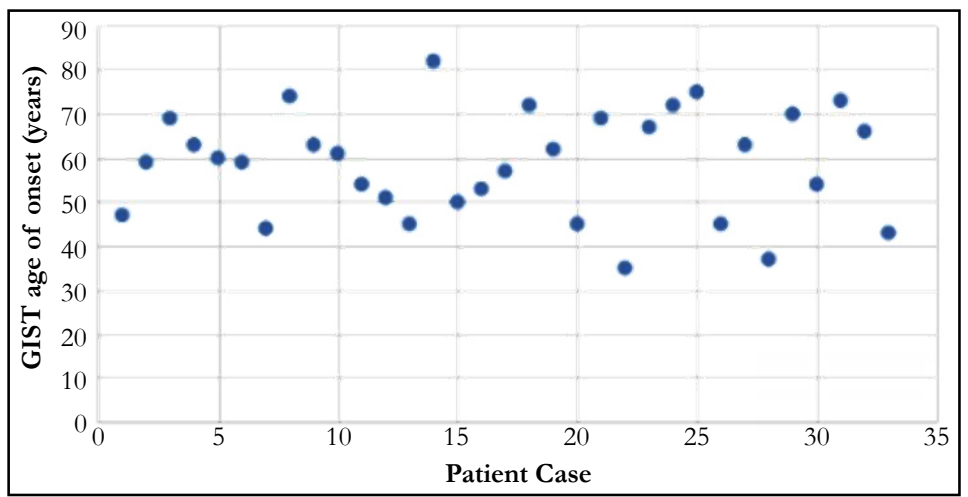

$(5.71 \%)$ and 1 in the greater omentum $(2.86 \%)$, disseminated in the abdomen.

\section{Recurrences}

Among the cases described, we found 5 recurrences of the primary tumor $(14.29 \%$ of the total): 2 cases in the small intestine $(40 \%), 1$ in the stomach, 1 in the colon, and the only in greater omentum, with lesions in the peritoneum and mesentery.

\section{Comorbidities}

In addition to the diagnosis of GIST, 5 of the patients $(14.29 \%)$ presented other secondary diagnoses apparently not associated with the oncological picture. Of these cases, four of them correspond to GIST located in the stomach, which associate incarcerated eventration and ovarian cyst in women, and hiatus hernia and cholelithiasis in men. In case of GIST in the small intestine, the secondary diagnosis corresponds to acute purulent peritonitis.

In all cases, they were repaired, performing an eventroplasty, unilateral adnexectomy, partial gastrectomy with abutment closure, cholecystectomy, and intestinal resection with manual anastomosis, respectively.

\section{Surgical approach}

$80 \%$ of the cases (28) were operated on by open surgery, with $60 \%$ of the gastric GIST, $93.33 \%$ of the GIST in the small intestine, and $100 \%$ of the GIST in the colon, pancreas and greater omentum. Only $20 \%$ could be operated by laparoscopy (7 patients), and in the case of gastric (46\%) and intestinal (8\%) GIST.

Of the 7 patients operated on by laparoscopy, 2 of them $(28.57 \%)$ had to be finally converted to laparotomy.

$91.43 \%$ of the interventions were performed by specialist doctors, and 3 interventions were carried out $(8.57 \%)$ by MIR, of which 2 of them were open surgeries (intestinal resection) and one by laparoscopy (partial gastrectomy), without the need for conversion.

\section{Surgical technique}

Fourteen gastric resections were performed, 5 of which were laparoscopic; all correspond to cases located in the stomach $(93.33 \%)$, in addition to an exploratory laparotomy, after which a partial gastrectomy was performed. For the cases of intestinal GIST, 12 resection were performed in the small intestine (80\%), a hemicolectomy (laparoscopic) and two exploratory laparotomies, which concluded in intestinal resection. The pancreatectomy performed as well as the total gastrectomy correspond to the cases of GIST in the pancreas. For cases of GIST located in the colon, a lumpectomy and a laparotomy were performed explorer (which included cystectomy). Finally, in the case of metastasis in peritoneum and mesentery, tumor excision was also performed (laparoscopic).

\section{Income and stay}

The majority of patients admitted to be operated on a scheduled basis $(85.71 \%)$, while in 5 cases they had to operate urgently, $100 \%$ of them using an open approach. The average length of stay was 10.91 days, being 9.14 days for patients undergoing laparoscopy, and 11.31 days for open surgeries. When analyzing the standard deviation of the three assumptions, we found a score of 8.23 for the average stay [Graph 2], 8.074 for the stay in the case of open surgery [Graph 3] and 9.28 for laparoscopic interventions [Graph 4].

\section{Reinterventions}

Of the 35 cases operated, three of them (8.57\%) had to be reoperated urgently by open approach, due to suture dehiscence. The first surgery was opened in all cases, since the only laparoscopy had to be converted. In the case of GIST of intestinal localization, an ileostomy was performed; in the other two cases, gastric GIST, drainage and lavage were respectively performed with intestinal resection, and total gastrectomy with esophago-jejunal anastomosis. A second reoperation was necessary in one of the cases of gastric GIST, to perform a colostomy, assuming the dissemination of the primary tumor.

\section{Complications}

Complications developed in 2 of the 35 cases: respiratory complication in a case of intestinal GIST; and double complication in a case of gastric GIST, in relation to splenectomy performed in the second surgical time, in addition to producing hematoma in the wound.

\section{Discussion}

Given these data we can make a comparative assessment between 
Graph 2. dispersion of the total stay time.

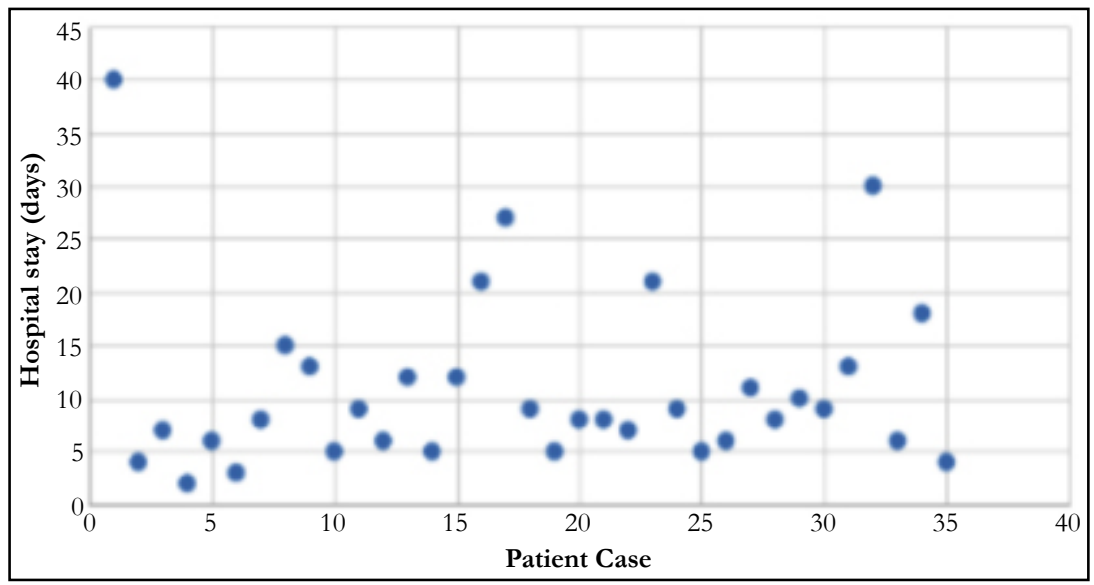

Graph 3. dispersion of the stay time in open approach.

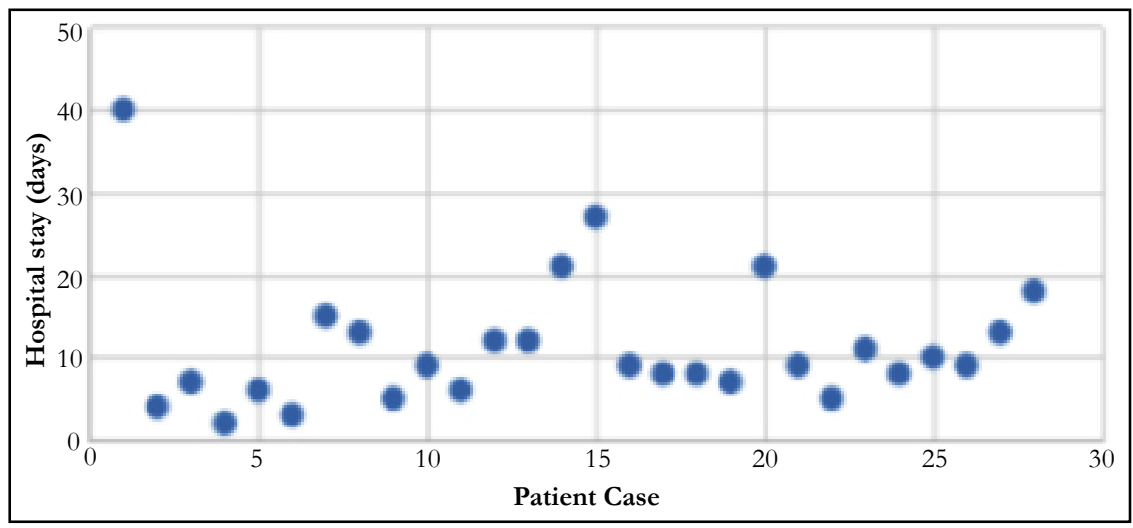

Graph 4. dispersion of the stay time in laparoscopic approach.

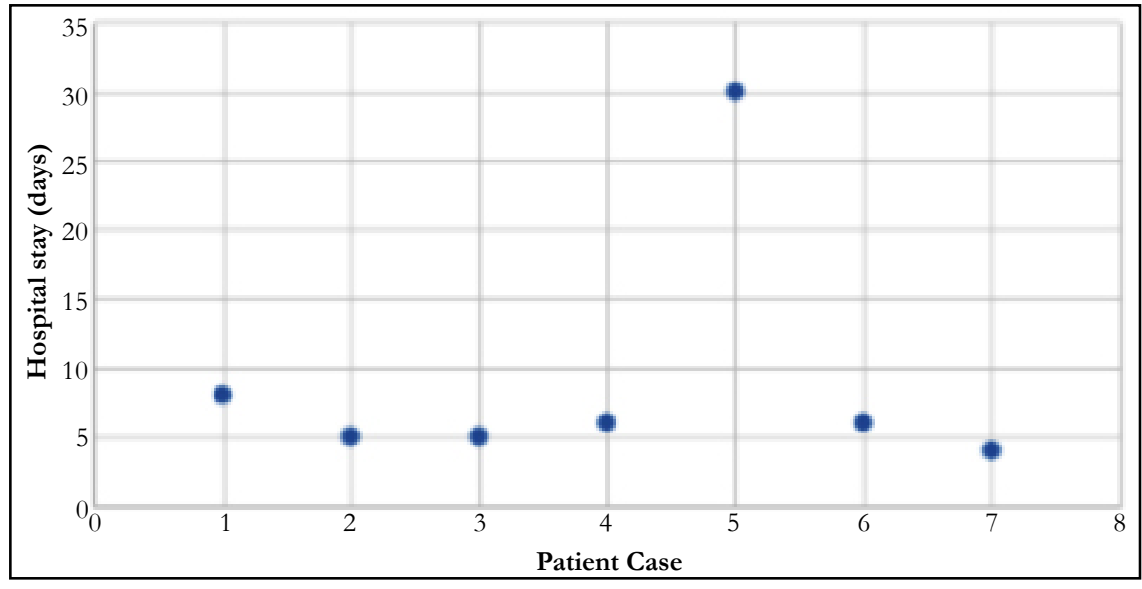

what was collected from the literature and our series of patients. First, and taking as reference the population assisted by the Hospital Virgen Macarena (481,296 inhabitants as of December 31, 2015), we found an annual incidence of disease of 16.62 cases per million inhabitants, based exclusively on clinical data, without knowledge of autopsies. The average age of appearance is located, corresponding to the described, between 55 and 60 years, without great differences between men and women, although there is a greater number of cases between 60-69 years (28.57\%).

Regarding tumor localization, in our series the appearance in stomach and small intestine are equalized, being within the statistics described for the first assumption (30\% - 50\%) but not for intestinal localization, whose mean of appearance is higher than the international average (42.86\%, above $20-30 \%)$ [15]. The cases located in the colon, $5.71 \%$, as well as the extragastrointestinals that were equally scarce $(5.71 \%)$ as expected. The latter are found in the pancreas, which is suggestive of primary tumor origin in stomach and local dissemination, as suggested in multiple publications. However, surprisingly, since they constitute the third location in frequency, we do not have cases of rectal GIST in our series, not even cases of GIST in the left colon or sigma, or extragastrointestinal locations of gynecological or urological type.

Given our descriptive study of cases treated surgically, we will only establish a comparison in relation to said data. We agree with 
the literature in which the gold standard for the surgical approach of GIST tumors is still open surgery, since the conditions for a minimally invasive approach are restrictive $[2,16]$ on laparoscopic treatment in gastric GIST. Thus, $80 \%$ of our patients were operated on in such a way.

Of the patients who met the requirements to undergo laparoscopy, $85.71 \%$ of these interventions corresponded to gastric GIST, where partial gastrectomies were performed without major complications. $28.57 \%$ of the laparoscopies performed had to be converted throughout the process, a high rate that reaffirms the importance of having the possibility of complications during surgery, using the appropriate safety measures during the resection and carrying out a rapid conversion in cases that require it, as recommended in the published series $[17,18]$ on reliability and laparoscopic resection effects in GIST. Thus, in more complex surgeries, such as the case of antrectomy or localized lesions close to the cardia, they were performed by open surgery, with subsequent Roux-en-Y gastrojejunal anastomosis and esophagogastric anastomosis, respectively.

For the GIST located in the small intestine, our data are consistent with those collected in the published series (1) on surgical management of GIST, with 12 segmental resections being performed in our center, all performed by open surgery. Likewise, in one of the cases recorded as intestinal, laparoscopic hemicolectomy was performed with ileojejunal anastomosis, in addition to unilateral anexectomy, which is why we assume that it was considered as such because it is a case of primary intestinal GIST with local dissemination. Given that the exact location of lesions in the small intestine is complicated by the tendency to extraluminal growth, it was necessary to perform exploratory laparotomy in two cases, one of them being a tumor recurrence that ended with a new intestinal resection. Since intestinal localization by itself constitutes a risk factor, as multiple series have suggested, it could be logical that $40 \%$ of the recurrence cases in our series are in this region.

However, 50\% of colon cases also correspond to recurrence, which may be related to the poor prognosis they associate [19]. For this case, exploratory laparotomy was performed after which implants of peritoneal carcinomatosis were removed and cystectomy was performed, most likely as part of palliative treatment, and provided that the benefit of a reoperation surpasses the possible surgical risks. For the other case of localization in the right colon, lumpectomy associated with appendectomy was performed.

As previously mentioned, the finding of pancreatic GIST is more suggestive of a gastric primary tumor with local dissemination than of a primary extragastrointestinal tumor [15], and could corroborate this. the two apparently pancreatic GIST cases included in our series. Specifically in one of them, a total gastrectomy, partial pancreatectomy and left hemicolectomy were performed, which makes us suspect not only of pancreatic dissemination but also of the colon, being of gastric origin, since they constitute the most frequent location. In the second case, intestinal resection is performed, without being clear what would be the primary origin.

We also include a case of soft tissue metastasis in our series, with the most frequent localization according to the experience of Gazmend et al., [1] and Agaimy et al., [5] on dissemination to distance in cases of GIST, together with the liver. Implants are found in omentum, small bowel mesentery and peritoneum, with probable primary origin in the small intestine, resecting the omentum, thus being a reductive non-curative surgery. Since surgery we have no record of previous chemotherapy treatments or possible resistance developed by certain foci, which would be the clear surgical objectives to delay the introduction of second line therapies. Thus, these lesions are resected in an attempt to increase progression free time, provided they are easily localized and the benefits of the intervention outweigh the risks, and although the chances of developing new foci are high.

Both the time of hospital stay and the postoperative complications that appear in our patients correspond to those derived from the general surgical action, without being specific to the pathology that concerns us. Similarly, it occurred in the three cases where it was necessary to reoperate urgently.

Initially there were 40 cases, of which 5 were excluded because surgery was not carried out. However, of all the cases that were intervened, in two of them, gastric GIST and small intestine, a benign histopathological diagnosis was reached. Thus, coinciding with what was collected in the literature $[2,6]$ a on the differential diagnosis of GIST at the immunohistochemical level, it was found a lesion in the ileum that turned out to be a leiomyoma, the most common differential diagnosis of GIST tumors. In the case of suspected gastric GIST, an intraoperative biopsy confirmed the benignity of the tumor, which in this patient would have led to a relapse.

\section{Conclusion}

The procedures applied to the pathology that concerns us are adjusted in our center to the protocols elaborated on studies of greater caliber and in populations of great significance. Likewise, our statistical results coincide with what is reported in the literature.

The low appearance of complications after surgery as well as the short mean stay indicate that the morbidity of our surgical treatment is minimal, although it is due to the lack of evolutionary data of the cases or to the authentic reliability of the process.

Regarding the use of open surgery versus laparoscopic approach, it does not influence significantly the choice regarding the total stay of patients.

The laparoscopic approach is more beneficial with respect to the appearance of complications that, although scarce, only appear in case of open surgeries.

Within the limitations of the study, we found that, although a specific analysis of the surgical aspects of GIST treatment was possible, the study is limited at this point, without knowing the prognosis and mortality associated with the patients treated in this way.

\section{References}

[1]. Gazmend R, Carlo B, Jacopo V, Tommaso D, Lorenzo C, Marco L, et al. Surgical Management of Gastrointestinal Stromal Tumours: A Large Single 
entre Experience. J Clin Case Rep. 2015;5(12):10-15.

[2]. Garlipp B, Bruns CJ. State of the art in the treatment of gastrointestinal stromal tumors. Gastrointest Tumors. 2014 May;1(4):221-36. doi: 10.1159/000380788. PubMed PMID: 26672673.

[3]. Niedźwiecki S, Piekarski J, Jeziorski A. The clinical and histopathological factors in patients operated on for gastric GIST tumors with unclear diagnosis. Adv Clin Exp Med. 2014 Jul-Aug;23(4):567-73. PubMed PMID: 25166441.

[4]. Janeway KA, Kim SY, Lodish M, Nosé V, Rustin P, Gaal J, et al. Defects in succinate dehydrogenase in gastrointestinal stromal tumors lacking KIT and PDGFRA mutations. Proc Natl Acad Sci U S A. 2011 Jan 4;108(1):314-8. doi: 10.1073/pnas.1009199108. PubMed PMID: 21173220.

[5]. Agaimy A, Wünsch PH. Lymph node metastasis in gastrointestinal stromal tumours (GIST) occurs preferentially in young patients $\leq 40$ years: an overview based on our case material and the literature. Langenbecks Arch Surg. 2009 Mar;394(2):375-81. doi: 10.1007/s00423-008-0449-5. PubMed PMID: 19104826.

[6]. Díaz Delgado M, Hernández Amate A, Sánchez León M, Pereira Gallardo S, Prieto Sánchez E, Jiménez Sáenz M, et al. Non-metastatic multiple gastrointestinal stromal tumors: Differential aspects. Spanish J Dig Dis. 2010 Aug;102(8):489-97.

[7]. Miettinen M, Sobin LH, Lasota J. Gastrointestinal stromal tumors of the stomach: a clinicopathologic, immunohistochemical, and molecular genetic study of 1765 cases with long-term follow-up. Am J Surg Pathol. 2005 Jan;29(1):52-68. PubMed PMID: 15613856.

[8]. Miettinen M, Kopczynski J, Makhlouf HR, Sarlomo-Rikala M, Gyorffy H, Burke A, et al. Gastrointestinal stromal tumors, intramural leiomyomas, and leiomyosarcomas in the duodenum: a clinicopathologic, immunohistochemical, and molecular genetic study of 167 cases. Am J Surg Pathol. 2003 May;27(5):625-41. PubMed PMID: 12717247.

[9]. Hassan I, You YN, Dozois EJ, Shayyan R, Smyrk TC, Okuno SH, et al. Clinical, pathologic, and immunohistochemical characteristics of gastrointestinal stromal tumors of the colon and rectum: implications for surgical management and adjuvant therapies. Dis Colon Rectum. 2006 May;49(5):609-15. PubMed PMID: 16552495.

[10]. Nakatani M, Fujiwara Y, Nagami Y, Sugimori S, Kameda N, Machida H, et al. The usefulness of double-balloon enteroscopy in gastrointestinal stromal tumors of the small bowel with obscure gastrointestinal bleeding. Intern Med. 2012;51(19):2675-82. PubMed PMID: 23037455.
[11]. Eckardt AJ, Adler A, Gomes EM, Jenssen C, Siebert C, Gottschalk U, et al. Endosonographic large-bore biopsy of gastric subepithelial tumors: a prospective multicenter study. Eur J Gastroenterol Hepatol. 2012 Oct;24(10):1135-44. PubMed PMID: 22797706.

[12]. Yeh CH, Pan KT, Chu SY, Chen CM, Hsu MY, Hung CF, et al. Safety and efficacy of image-guided percutaneous biopsies in the diagnosis of gastrointestinal stromal tumors. Clin Imaging. 2012 Jan-Feb;36(1):19-23. doi 10.1016/j.clinimag.2011.04.002. PubMed PMID: 22226438.

[13]. Joensuu H, Vehtari A, Riihimäki J, Nishida T, Steigen SE, Brabec P, et al. Risk of recurrence of gastrointestinal stromal tumour after surgery: an analysis of pooled population-based cohorts. Lancet Oncol. $2012 \mathrm{Mar}$;3(3):26574. doi: 10.1016/S1470-2045(11)70299-6. PubMed PMID: 22153892

[14]. Catena F, Di Battista M, Ansaloni L, Pantaleo M, Fusaroli P, Di Scioscio $\mathrm{V}$, et al. Microscopic margins of resection influence primary gastrointestinal stromal tumor survival. Onkologie. 2012;35(11):645-8. doi: 10.1159/000343585. PubMed PMID: 23147540.

[15]. Miettinen M, Lasota J. Gastrointestinal stromal tumors: pathology and prognosis at different sites. Semin Diagn Pathol. 2006 May;23(2):70-83. PubMed PMID: 17193820.

[16]. Lin J, Huang C, Zheng C, Li P, Xie J, Wang J, et al. Laparoscopic versus open gastric resection for larger than $5 \mathrm{~cm}$ primary gastric gastrointestinal stromal tumors (GIST): a size-matched comparison. Surg Endosc. 2014 Sep;28(9):2577-83. doi: 10.1007/s00464-014-3506-x. PubMed PMID: 24853837.

[17]. Smolarek S, Pomeroy E, Kinnarney F, Arumugasamy M. Laparoscopic resection of large gastric gastrointestinal stromal tumours. Wideochir Inne Tech Maloinwazyjne. 2016;11(1):31-37. doi: 10.5114/wiitm.2015.56489. PubMed PMID: 28133498.

[18]. Chi JL, Xu M, Zhang MR, Li Y, Zhou ZG. Laparoscopic Versus Open Resection for Gastric Gastrointestinal Stromal Tumors (GISTs): A Size-Location-Matched Case-Control Study. World J Surg. 2017 Sep;41(9):23452352. doi: 10.1007/s00268-017-4005-8. PubMed PMID: 28349318.

[19]. Miettinen M, Sarlomo-Rikala M, Sobin LH, Lasota J. Esophageal stromal tumors: a clinicopathologic, immunohistochemical, and molecular genetic study of 17 cases and comparison with esophageal leiomyomas and leiomyosarcomas. Am J Surg Pathol. 2000 Feb;24(2):211-22. PubMed PMID: 10680889 . 